\title{
Community leaders as intermediaries: how everyday practices create and sustain leadership in five informal settlements in Cape Town
}

\author{
Elmé Vivier (Nottingham Business School, UK) and Diana Sanchez-Betancourt (Human \\ Sciences Research Council, South Africa)
}

The final version of this manuscript has been published and is available in Leadership, July 2020, DOI: https://doi.org/10.1177/1742715020940907

\begin{abstract}
Community leaders are expected to navigate between different social and institutional contexts, but they must do so without the direction, authority or legitimacy available to leaders within formal organizations. In this article, we draw on qualitative data from a participation initiative to explore how community leaders get involved in everyday maintenance of public services in informal settlements in Cape Town, in order to understand how they fulfil this intermediary role. Applying the lens of leadership-as-practice (L-A-P), we identify four practices that connect the communities and city, and which facilitate access to public services. We unpack how these practices emerge in and are shaped by the service maintenance system and material conditions of informality. We argue that community leaders fulfil their intermediary role through everyday improvisations to find 'what works', and in the process, they also create and sustain relations of dependence and interdependence that reinforce those very roles.
\end{abstract}

Key terms: community leadership, leadership-as-practice, legitimacy, power, service delivery, informal settlements

\section{Introduction}

In post-apartheid South Africa, the delivery and management of services in informal settlements remains an urgent priority (Govender, 2016). While government reach within informal areas is limited (Drivdal, 2016), community leaders have come to play an important role in the governance of local services. Yet there are few studies of leadership, or even community leadership, that examine community leaders in developing country and informal settlement settings (Bénit-Gbaffou and Katsaura, 2014). The extant literature describes community leaders as 'situated agents' (Munro, 2008) whose roles and practices are socially 
constructed in context. This context is not, however, that of formal organizations with clear agendas and hierarchical structures. Rather, community leadership contexts may comprise local organizations with formal leaders, but also alliances between different actors working together to address a particular issue, or informal leaders representing "communities of place" (Brint, 2001). The latter often characterizes leadership in informal settlements (Drivdal, 2016), where informal leaders do not have a clear agenda and mandate to guide them. Despite such diversity, scholars also commonly describe community leadership as situated between the structures and policy directives of formal organizations (e.g. government), and communities' more informal ways of organizing (Welton and Freelon, 2018; Gambrell, 2016; Martiskainen, 2017). This requires local leaders to navigate between these contexts, taking on an 'intermediary' role (Bénit-Gbaffou and Katsaura, 2014). Again, however, they must do so without the clear direction, authority or legitimacy provided to leaders within organizations. As Schweigert $(2007 ; 326)$ explains, community leaders remain pressed between "overlapping layers and shifting sources of influence, resistance, and negotiation", but with "no fixed position of superiority". In this paper, we explore this intermediary role in the context of informal settlements in South Africa and ask, how do community leaders fulfil this intermediary role and navigate the multiple pressures and expectations from communities 'below' and government 'above'?

To gain insight into the intermediary role of community leaders, we draw on the concept of leadership-as-practice (L-A-P) and explore the intermediary practices between local government and informal settlement communities in South Africa. The practice lens in leadership theory shifts attention away from individual competencies to leadership understood as "an agency emanating from an emerging collection of practices" (Raelin, Kempster, Youngs, Carroll and Jackson, 2018: 372). Simpson (2016) describes it in terms of a set of socially defined practices or situated 'doings', emerging in the ongoing flow of practice. L-A-P also considers the everyday, lived experiences and mundane work of leadership (Carroll, Levy and Richmond, 2008; Raelin, 2016a; Kempster and Gregory, 2017), with the potential to articulate the intersection of individual agency and social systems and practices (Nicolini, 2013). This allows a view into how certain social practices may enable individuals to emerge and act as leaders.

At the same time, scholars employing this lens often portray L-A-P as inherently collective and non-hierarchical, and thereby overcoming the power differentials embedded in the leaderfollower relation (Raelin, 2016a; Woods, 2016). Others (Collinson 2018; Ford, 2016; Carroll in 
Raelin et al., 2018), however, have argued L-A-P's emphasis on collective agency and interdependence fails to adequately account for how power asymmetries still manifest and operate in leadership-as-practice. In this regard, we find the concept of community leadership contains a similar tension between, on the one hand, the notion of collective leadership agency, and on the other hand, the intermediary role of individual leaders that may enhance power asymmetries. We aim to contribute to this discussion by exploring how community leadership is socially constructed through specific practices, but practices which enable individual leaders to act as intermediaries.

The paper is structured as follows. In the next section, we discuss theoretical linkages between the concept of leadership-as-practice and studies of community leadership. In the community leadership literature, we observe a tension between leadership understood as a form of collective agency, and leaders acting as intermediaries. We then briefly discuss the notion of leadership legitimacy and the need for community leaders to navigate upwards and downwards pressures for legitimacy, which we later apply as an interpretive frame to analyze community leaders' practices in the empirical data. This is followed by a description of our research methods. The qualitative data is drawn from a participatory project conducted in five informal settlements in Cape Town. We then explore how the ten community leaders who participated in the project get involved in aspects of electricity and water management. From the narratives of the leaders, we identify four key practices that show how they act as intermediaries. We argue that they resolve the tensions at the center of this role, not through extraordinary interventions but through pragmatic improvisations to find 'what works' in everyday township life. As their practices emerge in the complex interplay between government and community systems and their shortcomings, they also create and sustain relations of dependence and interdependence that reinforce those very intermediary roles. In the final section, we reflect on what this may suggest for understanding community leadership.

\section{Community leadership through a leadership-as-practice lens}

The post-heroic leadership paradigm can broadly be described as an approach that underscores social, relational, material and contextual dynamics rather than the qualities, traits or competencies of the individual leader (Fletcher, 2004). This has alternatively been referred to as a social constructionist approach that includes a wide array of leadership typologies, such as shared, distributed, collaborative, collective, systemic and complexity leadership (Uhl-Bien and Ospina, 2012). These describe leadership as emerging in, and shaped by, dynamic social organizing processes (Uhl-Bien, 2006). Such a view is also evident 
in theorizations of community leadership, which Lauzon (2017) defines as "a social process" involving collective agency and action. There seems, however, to be little explicit engagement between the community and post-heroic leadership literatures, and especially with the emerging concept of leadership-as-practice.

\section{Leadership-as-practice}

Leadership-as-practice (L-A-P) marks an emerging concept and research lens within leadership studies, with many synergies with the post-heroic paradigm (Collinson, 2018). Whether L-A-P constitutes a subset of the post-heroic paradigm or a distinct approach is not our concern here (for more on this debate, see Collinson, 2018 and Raelin et al., 2018). But L-A-P is still in the process of conceptual articulation, operationalization and debate, with scholars acknowledging limited empirical research from different contexts (Raelin et al., 2018; Kempster and Gregory, 2017). Influenced by the so-called 'practice turn' within social and organization theory (Carroll et al., 2008; Schatzki et al., 2001), L-A-P focuses on how leadership emerges within the continual flow of 'practice', where the world is understood as a processual, recurrent accomplishment (Simpson, 2016; Kempster and Gregory, 2017). It also explores leadership as 'a set of practices' (Crevani and Endrissat, 2016: 23, 31) through which things 'get done' (Raelin, 2016b). This includes mundane, every day, habitual practices (Raelin, 2011; Carroll et al., 2008), but also improvisations that unexpectedly disrupt and reorient the flow of activity (Simpson, 2016). The practice lens therefore illuminates how practices shape and are shaped by context (Endrissat and von Arx, 2013; Fisher and Robbins, 2015). By de-centring the individual as the source of agency and action, studies in L-A-P unearth contextualized "patterns of connected action" (Crevani and Endrissat 2016: 25).

Emphasizing the 'doings' rather than the 'doers' of action (Simpson, 2016), L-A-P is less concerned with identifying patterns of individual practices, which may reinforce the usual assumptions around individual influence and control (Ford, 2016). Raelin (2016b) therefore describes L-A-P as 'intrinsically collective' and a 'collaborative agency'. It is about what people accomplish together, thereby challenging the hierarchical relation between an active leader and passive followers. At the same time, however, Raelin (2016b: 4) recognizes that, depending on the situation, certain individuals may still be important and "leadership may emanate from the actions of particular individuals". As organization scholar Davide Nicolini (2012: 42) explains, practice theory enables understanding of how individuals are "carriers of the system", reproducing it in practice, but also potentially introducing variation and change. There is not a single, unified practice theory to explain this dynamic, however (Nicolini, 2012). 
With regard to L-A-P, Youngs (in Raelin et al., 2018), thus argues against a strict dichotomization between the individual and collective (or heroic and post-heroic approaches), which may produce an oversimplified understanding of how practice unfolds. (That the heroic and post-heroic approaches make different ontological assumptions is beyond the scope of this paper, but for a comprehensive discussion on this point, see Uhl-Bien and Ospina, 2012). The pertinent point for us is twofold. First, according to Crevani and Endrissat (2016), many empirical studies in LAP still focus on formal leaders, including their practices as well as motivations/intentionality, and this is a shortcoming, they argue. Methodologically, we also focus on individual leader practices in this paper, although we view these as an entry point for understanding certain patterns of activity through which things 'get done', including producing particular leadership roles. Second, the role of individual leaders vis-à-vis a 'collective' is precisely where the intermediary role of community leaders comes to the fore, potentially illuminating how power - a key point of discussion within L-A-P scholarship - emerges and operates.

On the one hand, L-A-P lends itself to a perspective of collaborative agency embedded in democratic values (Woods, 2016), precisely because it moves away from a leader-follower hierarchy. On the other hand, L-A-P is "not of necessity or by definition fair and democratic" (Woods, 2016: 73). As Raelin (2011) acknowledges, practice can also involve contestation, divergence, exclusion, and conflict (see also Crevani et al., 2010). According to Nicolini (2012: $6)$ :

Practices, in fact, literally put people (and things) in place, and they give (or deny) people the power to do things and to think of themselves in certain ways. As a result, practices and their temporal and spatial ordering (i.e. several practices combined in a particular way) produce and reproduce differences and inequalities.

For Collinson (2018), however, the emphasis on collective agency and leadership coconstruction within L-A-P still risks neglecting how unequal power relations may persist, and marks a weakness of L-A-P vis-à-vis Critical Leadership Studies (see also Fletcher, 2004). Similarly, Ford (2016: 223) argues that L-A-P may miss how 'long established patterns and institutionalized norms' that shape social relations and marginalize certain voices may be perpetuated in practice.

Can L-A-P enhance our understanding of how power manifests and is exercised within contextually-produced practices? According to Carroll (in Raelin et al., 2018), there are many 
layers of power relations to consider. While broader patterns of structural inequality remain significant, L-A-P enables a different perspective on power, and "looks for power at the point it emerges, becomes visible, or is accomplished by both human and material agents" (2018: 378). This, she continues, often occurs at the micro level, in subtle dialogical moments and everyday interactions. It is the 'ambiguous space' of 'soft' power. Simpson (2016: 169) describes it as 'coactive power', or 'power with', as distinct from power "as some 'thing' that can be acquired, possessed, and exercised over others". Power from this perspective is not a property or entity but flows through practices and relations (Simpson, 2016). Still, there seems to be some agreement among scholars that greater attention is needed within L-A-P studies to how power manifests, permeates and operates within contextual practices (Kempster, in Raelin et al., 2018: 374).

Although the question of power in L-A-P is not the primary focus of this paper, it is pertinent to the discussion of community leadership. That community leadership exists outside of organizational hierarchies may seem, on the surface, to lend itself well to a theorization of leadership-as-practice where notions of collective engagement have been employed. However, the intermediary role of community leaders challenges precisely such a collective, non-hierarchical view of agency. It is to these two aspects of community leadership that we now turn.

\section{Community leadership: from collective action to individual intermediaries}

While there are studies of community leadership that focus on individual character traits (Nowell et al., 2016), there are also theorizations of community leadership that resonate with relational, constructionist and practice approaches. Within this subset of literature, community leadership is described as a dynamic and emergent social process (Lauzon, 2017; Martiskainen, 2017), constituted by social contexts, relationships and processes (Schweigert, 2007). This suggests community leadership is not defined by organizational structures and formal leader-follower hierarchies (Martiskainen, 2017). Rather, it is seen as non-hierarchical, involving forms of community organizing and collaborative action (Nowell et al., 2016). For Ivory (2008), community leadership involves a web of relations and practices (or 'networked leadership') that endures the shifting involvement of individuals and groups. Even in studies that identify specific community leaders, scholars often point towards practices of 'collective power', 'participation' and 'collaboration', as well as the importance of shared knowledge and decision-making (Brail and Kumar, 2017; Ivory, 2008; Lin et al., 2017; Onyx and Leonard, 2011; Welton and Freelon, 2018). 
At the same time, studies of community leadership acknowledge individual leaders, whether formal or informal, acting as intermediaries between different stakeholders, interests and institutional systems (Bénit-Gbaffou and Katsaura, 2014; Welton and Freelon, 2018; Gambrell, 2016; Martiskainen, 2017; Ivory, 2008; Purdue et al., 2000). This intermediary role may be practiced and felt in a variety of ways. As intermediaries, community leaders may bridge community needs and service provision (Lin et al., 2017), bring collective inputs into government development plans (Brail and Kumar, 2017), translate new information and concepts into local contexts (Martiskainen, 2017), and facilitate network engagements to mobilize resources (Ivory, 2008; Majee et al., 2017). They can do so through a mixture of quite ordinary practices, such as attending meetings of different organizations (Lin et al. 2017). In a study of community leadership in Indigenous communities in Australia, Ivory (2008) describes how such intermediary practices become especially pertinent where major changes occur in the broader social context, such as the arrival of European settlers and missionaries, as well as more recent local government reforms. Despite the collective and egalitarian leadership systems in place, Ivory (2008) observes how individual leaders responded differently, either building new relationships or distancing themselves and their communities from these changes.

In the context of informal settlements in Cape Town, Drivdal (2016) identifies similar practices among community leaders as they get involved in specific activities, some related to the management of municipal services. For instance, she finds that leaders interact with external organizations, participate in meetings, and carry out administrative tasks such as distributing information to residents, "counting and numbering shacks", and "monitoring the settlements regarding, e.g. waste" (2016: 283). These tasks often emerge as part of local upgrading projects. On-going, everyday activities identified by Drivdal tend to pertain to 'internal' matters such as mitigating conflicts between neighbours. Leaders' on-going work in service maintenance is not the main focus for Drivdal, however, and it is to these kinds of practices that this article will zoom in.

To make sense of how community leaders take up their intermediary role, and how being situated 'in between' informs their practices, Bénit-Gbaffou and Katsaura (2014) employ the Bourdieusian concept of political capital. Because community leaders lack any "fixed position of superiority" (Schweigert, 2007) available to organizational leaders, they must continually work to obtain legitimacy with their constituencies ('the bottom') and with institutions such as 
government ('the top') (2014: 1809). The pressure to gain legitimacy in these two directions provides an interpretive frame for understanding how and why leaders take up their roles in the flow of activity and in the context of these different relationships. According to the authors (2014), leaders' legitimacy with their community depends largely on their representativeness, or the extent to which they are seen to belong, to be 'one of us' and able to speak on behalf of local interests. It also depends on their ability to deliver and resolve individual and/or collective issues. This ability derives from leaders' local knowledge and political skills (e.g. knowing the rules of the game, being able to articulate themselves in public meetings), as well as their visibility and approachability. Similarly, with the 'top', community leaders may gain legitimacy through a show of loyalty and support to the institution (i.e. they are perceived as not too radical), and also as 'entry points' into their communities. Bénit-Gbaffou and Katsaura (2014) give examples of leaders who are able to mobilize residents for a march (a show of legitimacy with the bottom), but also able to get high-level officials to sign a petition or speak at an event (a show of legitimacy with the top).

Unsurprisingly, navigating these upwards and downwards pressures require leaders to balance conflicting expectations, loyalties, and logics (Purdue et al., 2000; Welton and Freelon, 2018; Gambrell, 2016). This can be especially challenging for leaders who caught between what Massey (2015: 303), in reference to informal settlements in Cape Town, describes as "conflicting governmentalities" between a technocratic, neo-liberal government and the organic systems of communities. Buire (2011) confirms this simultaneous 'upward' and 'downward' pressure on leaders, finding the Cape Town municipal system and daily neighbourhood life constitute two distinct yet 'cohabiting' forms of legitimacy. The intermediary role thus requires leaders to act at the intersection of different social systems, norms and patterns of activity. Stated otherwise, through the concept of legitimacy, we can begin to make sense of how leaders navigate these different systems and become intermediaries. Drawing this back to L-A-P, we are also interested to explore how power manifests and operates in this process.

\section{Research methods}

The qualitative data used in this article were collected through a pilot project implemented between 2014 and 2015 that involved community leaders and officials from the City of Cape 
Town, and adapted a community-based monitoring method called a community scorecard. ${ }^{1}$ The purpose was to involve officials and community leaders in finding constructive ways for these often antagonistic actors to engage with one another. The project focused on how water and electricity services are provided and maintained, as well as on interactions between local leaders, residents and officials. It involved six months of preparatory discussions and research, and three weeks of joint workshops and site visits. Although investigating community leadership was not a project objective, workshop discussions offer insights into how the leaders understand and exercise their leadership in relation to service maintenance.

The participants included ten community leaders from five informal settlements (two from each settlement), and approximately 15 officials from 12 departments. Some activities also involved a number of residents from the settlements. As the research and facilitation team, we met with the ten leaders several times over the course of the project, and they insisted that we always meet with them together. They are elected, although how these elections happen are not entirely clear. The ward councillor at the time insisted on annual elections for the leaders, and this created deep tensions between the leaders and the councillor. At the time of the project, eight of the ten leaders were women, and some of them had been leaders in their communities for twelve years or more. Since we were not focusing on leadership during the project, it is not clear how the leaders originally became involved in community matters and became leaders. Drivdal (2016) offers important insights into the ways people become leaders in informal settlement settings. These include: gaining a reputation among residents of being able to resolve social conflicts; getting involved with external organizations and their activities; and being installed as leaders through the deliberate efforts of external actors (Drivdal, 2016).

During workshop discussions, both leaders and officials described their practices in detail, including their daily experiences and efforts around maintenance. Data were collected through participant observation (by two researchers and one external facilitator). Audio recordings of

\footnotetext{
1 The community scorecard is a participatory method intended to enhance accountability and improve service delivery. It involves 'service users' and 'service providers' in the development and application of 'indicators' to evaluate services (Gullo, Galavotti and Altman, 2016; Ho et al., 2015). Community and government participants are guided through a discussion of their daily experiences with the selected service, and the issues raised are translated into a set of questions constituting a 'scorecard' for evaluating service delivery. In joint workshops, participants inspect, evaluate and discuss the infrastructure through site visits, and identify possible solutions. Community scorecards have been implemented in various developing countries (e.g. Ethiopia, India, Madagascar, Malawi, Uganda, Rwanda and Tanzania), predominantly focused on health and education in rural areas. The scorecard in Cape Town was piloted in an urban informal context and examined water and electricity (see author names omitted for peer review, 2019).
} 
each meeting and workshop were transcribed, and field notes written during and after each event were also included as data. The data were then analysed abductively. First, each transcript was coded through open coding of what leaders do in their communities. This was applied to sentences, longer passages, and exchanges between different participants. Through a second round of coding, we used thematic analysis to identify recurring themes and patterns across the different sources and chunks of data. From this, we noticed four key practices used by leaders that 'intervene' at certain points in the city's service delivery and management process, as well as between the city and residents. We explored these practices through an iterative engagement with the community leadership literature, identifying overlaps and potential expressions of legitimacy. A follow-up workshop in 2016 was also used for perception checking and exploring specific gaps. Limitations of the study include the lack of residents' perspectives, as well as limited data to assess the commonality of practices. However, this article does not intend to produce generalizable explanations (Krefting, 1991), but rather to offer an understanding of how certain practices mediate between communities and the City, and produce and legitimate community leadership in context-specific ways.

\section{The context}

\section{Infrastructure maintenance in informal settlements}

Informal settlements in South Africa must be understood in the context of apartheid, which forced the black African majority to the urban periphery while purposefully neglecting service provision to those areas (von Schnitzler, 2008). With over one million households residing in informal settlements (Housing Development Agency, 2013), urban spatial transformation, including socio-economic integration and the provision of quality infrastructure, remains a major task (Cameron, 2005). In Cape Town alone, approximately 146,000 households live in 437 informal settlement pockets (with only 204 officially recognized) (ismaps.org.za, no date). Service management and maintenance therefore become especially important for the longterm operation and sustainability of available infrastructure. However, the provision of substandard and 'emergency' forms of services for unspecified and long-term duration (McFarlane, 2008) exacerbates the need for, but also difficulty of doing maintenance. Challenges are commonplace and include, inter alia, the maintenance of: sufficient supply of safe quality water; clean and functioning sanitation facilities; public lighting to ensure safety and safe access to other public services; proper electrical equipment to reduce the risk of fire; and roads and storm water drains to reduce the risk of flooding (McFarlane, 2008; Williams et al., 2018). 
That there is a role for leadership in service and infrastructure maintenance is not obvious, however. Leadership scholars have commonly distinguished leadership, understood as the articulation of vision, meaning-making and the accomplishment of change, from management, defined as the ordering of operations and task implementation (Kotter, 1990; Madumo, 2012). But there is emerging recognition that operational, motivational and meaning-making practices intermingle in the policy implementation process (Ospina, 2017). In fact, addressing service delivery challenges in informal settlements is far from a routine technical matter where difficulties can be resolved through engineering or management expertise. Govender (2016), for instance, has detailed how service delivery in South Africa constitutes a wicked problem (Rittel and Webber, 1973), especially given the durable spatial form of the apartheid city. Ongoing delivery, maintenance and repair of infrastructure services are also often the primary way in which citizens experience and interact with local government. Given the limited reach of government in informal areas (Drivdal, 2016), this suggests service maintenance offers an important context for the practice of community leadership.

\section{The Heights}

The five informal settlements where the research took place, known collectively as The Heights, are located in a diverse ward in the southern region of the Cape Town metro. The settlements are concentrated in an area of the ward predominated by formal housing $(18 \%$ of dwellings are informal or backyard shacks). The average household size is five people, and unemployment is approximately $42 \%$. According to the community leaders, the settlements were established in the 1970s. Despite the provision of government-subsidized housing in 2005, people from other areas "invaded" and occupied most of the dwellings. Residents struggled for many years to eventually receive basic services of communal taps, toilets and electricity. The settlements vary in size: the smallest comprises 41 dwellings compressed in one street block, while the largest comprises 2000 dwellings across a much larger area.

According to data provided by the City, service levels across the five settlements vary drastically. At the time of the research, some areas reportedly have one communal tap for every three households, with the worst areas having only one tap per 56 households. The City's target ratios are one tap for every 25 households, and one toilet for every five households (Storey, 2014). For electricity, pre-paid meters are available in most households, although a few areas remain without any electricity. Many other challenges persist, with electricity infrastructure regularly failing or being vandalized. There are also major issues with 
gangsterism, crime and drug addiction. It is in this context that we explore the practices of the ten community leaders.

\section{Community leadership practices emerging in service maintenance}

How do community leaders act as intermediaries and navigate pressures from above and below? In this section, we discuss four practices that seem to have emerged in the context of electricity and water maintenance: reporting services issues; contacting and meeting officials; preventing vandalism; and defending illegal connections. Community leaders use these practices to gain and maintain legitimacy as leaders and intermediaries in relation to both the City and their communities.

\section{Reporting service issues: accessing the city}

One of the main tasks of community leaders is to report service issues to the City. These include specific issues, such as when streetlights go out, electricity boxes catch on fire, or water pipes burst. The City has established a notification system that allows residents to phone or send a text to a central call centre that directs each complaint to the appropriate department. Although intended to de-personalize access to the City, in informal areas it is often through direct communication between officials and local leaders that the system actually becomes effective.

In informal settlements, systems and practices around reporting service faults bring up issues related to local political representation. Although the notification system provides residents and leaders with an alternative to going through the ward councillor, their formally elected political representative, it does not mitigate their frustrations with him and leaders generally perceive him as unreliable (Workshop 1, 16 March 2015). Such perceptions are not unique to these communities, and research on informal settlements across Cape Town has found citizens are largely dissatisfied if not distrustful of local representatives (Thompson and Nleya, 2010). In this case, however, the leaders explain their frustrations in terms of the councillor's ineffectiveness in reporting problems, which results in residents asking the leaders to report service faults on their behalf. In the excerpt below, two leaders and one of the facilitators try to identify why the City's response to issues in one settlement is much better than in another:

Facilitator: So, are you saying that you get a better response from the city in Overcome than you are having in Military? And why do you think that is?

Leader A: You must deal with the right people.

Facilitator: Is it the people you're dealing? Are you dealing with different people?

Leader A: I don't know who... 
Leader B: Sometimes they go to the councillor and tell him the complaints that they have; and it will take ages. Whereas we phoned directly to the people [...] and they will send out people. [...] So that is their chairperson; I don't think she have all the numbers, that is why they go to the councillor, and the councillor just log it in, and that's it. Nobody's taking note, or go further and ask them, listen here, is that what is the problem, is the problem sorted out or things like that (Workshop 1, 16 March 2015).

In this exchange, the leaders challenge the legitimacy of the ward councillor, despite his formal leadership position, on the basis of a pragmatic need and what they perceive as his lack of support for the community. He does not 'belong' in the way that they do, because he fails to 'deliver' by relaying service faults to the City or following up to make sure the problem gets fixed.

Conversely, the community leaders' legitimacy with their constituencies emerges through their efforts to monitor for problems, their knowledge of the notification system, and their willingness to call "with our air time" (Workshop 1, 16 March 2015). This is evident in the following quote where a leader explains her frustrations with having elections in their settlements every year:

Leader B: Can you see what's happening? The ward councillor comes in and then he say, okay you have to have an election. And now all of a sudden there's an election and now she comes on board; l'm out as the chairperson [...] At the end of the day this lady doesn't know anything, she doesn't have the numbers. Now at the end of the day our community is suffering. That is what happens (Workshop 1, 16 March 2015).

Leadership is thus constructed in the positive image of the leaders who are knowledgeable because they have the number to the call centre. While this number is posted on refuse containers throughout the settlements, the community leaders use this point again and again to show the failures of the councillor and to claim their own legitimacy and commitment to the community.

Although it is possible that the leaders may exaggerate the extent to which residents come to them to report problems (perhaps to gain legitimacy with the researchers), Drivdal (2016) found a similar situation in other settlements regarding the reporting of crime and vandalism. It could therefore be that residents go to their local leaders rather than use the notification system precisely because leaders have historically played such an intermediary role in their communities and are by default closer and more accessible. The notification system represents a new governance mechanism that has yet to replace existing and embedded social practices and relations. If this is the case, the City's communication of this mechanism might not yet be sufficiently effective to transform reporting practices (for similar findings, see Masafu, 2015). 
While the call centre's 'direct line' to the City may overcome some of the tensions between the councillor and community leaders, repair of infrastructure is not simply a matter of reporting but also of responding. In this regard, community leaders play a central role in providing access to the settlements for officials and technicians.

\section{Contacting and meeting officials: accessing the community}

Officials who participated in the project raised concerns about their ability to respond to service faults due to logistical and social issues. This included residents not having addresses, or moving their shacks and taking their addresses with them, both of which makes it difficult for technicians to locate reported problems (Workshop 3, 17 March 2015). Among the social challenges, gang violence and the safety risks this poses for officials were a major concern, with some areas considered too dangerous for officials to enter. In instances of major electricity outages, a police escort has been used (Workshop 3, 17 March 2015). Such conditions have direct implications for the repair of infrastructure, as well as for the emergence of an important leadership practice. Once a problem has been reported, officials rely on local leaders to communicate when it is safe to enter, and then to meet and assist them in locating the problem. As one official explained:

In that area, there's two ladies there who deal directly with us. They will phone us directly and say, 'Don't come in, there is a gang war taking place so we'll let you know when you can come in.' Sometimes we need to just wait for them to get back to us. [...] But if they're not available, then we can't just go into the area (Workshop 3, 17 March 2015).

From the perspective of the leaders, this is one of their responsibilities: to ensure officials do not get hurt or robbed, because "they're scared" and "they're only human", but also because otherwise the problem doesn't get fixed (Workshop 1, 16 March 2015).

In this way, the leaders function as the 'eyes and ears' of the City, although they are not simply responding to instructions from the City or performing tasks for the City. Rather, their assistance to the City has become part of retaining their legitimacy with their communities. In other words, the leaders' ability to deliver to their communities evidently also depends on the City's ability to respond - to physically show up and fix the problem. At the same time, officials' ability to respond depends to some degree on the leaders' legitimacy in their communities in the first place. The leaders can take officials to specific service faults and provide some security for technicians because they 'belong'; they have established relationships and networks with residents and thus have knowledge of what is going on. By meeting officials and helping them address problems, the leaders can simultaneously showcase their local 
'power' and relevance, and their access to and 'power' with the City, thereby reinforcing their legitimacy with both the City and their communities.

\section{Preventing vandalism: protecting services}

A major issue in the five informal settlements, recognized by both leaders and officials who work in the areas, is vandalism and general 'misuse' of infrastructure. In one of the City workshops, vandalism was noted as a major concern, with all infrastructure being continually misused and/or broken (Workshop 3, 17 March 2015). These concerns were further reflected in officials' views that communities should "take ownership" of the infrastructure, so that "it becomes their taps, it becomes their water, it becomes their infrastructure" (Workshop 3, 17 March 2015).

The community leaders expressed similar frustrations with a lack of ownership by residents. They described how they address vandalism by phoning and shouting at specific culprits for damaging taps or wasting water, or even phoning the police in cases of theft. These practices can be understood as part of the internal mediating role of leaders, also noted by Drivdal (2016) in her analysis. These are not formally instituted practices but are rather ad hoc and often depend on residents putting pressure on the leaders, or leaders taking notice of certain individuals and behaviours. These practices are likely to generate legitimacy with both the bottom' and 'the top' as residents and officials see the leaders taking care of the shared infrastructure and resources. Indeed, officials who participated in the project reported improved views of the community leaders once they heard leaders share their concerns and try to act on vandalism (Workshop 4, 6 April 2015).

\section{Defending illegal connections: accessing services}

Efforts to prevent and address vandalism seem, however, to contrast directly with how community leaders sometimes 'manage' illegal connections. In the following exchange, two leaders discuss the fact that water taps are communal and thus erected in the street, yet it is possible for someone to move it into their yard:

Leader A: If a single house can have maybe a R50 or whatever, you can have the tap in your house, to make it convenient for yourself. Because we don't know how long we're still gonna live like this. [...] Now what we did there, we bought the pipes, we bought our fittings and everything, and take it from the road and...

Facilitator: And you've done that privately?

Leader A: Ja, because you must make it convenient for yourself. Because if you don't help yourself no one will help you.

Leader B: The only problem is that if we do that and there's a problem with that pipe and we phone them and they come in and say, but this is illegal. Then we have to come up for each other: 'listen man, this is an old lady, rather leave that person'. [...] That is the way to make it convenient for each other (Workshop 1, 15 March 2015). 
In this dialogue, the leaders justify illegal connections (some even reported doing it themselves), through claims to individual responsibility for one's dignity and comfort. This suggests a different kind of legitimacy and sense of community at play, one centred on 'coming up for each other'. What comes to the fore here is the fact that leaders share with residents the conditions of living in informality - they understand the local reality and the uncertainty of any future housing and infrastructure development. The leaders must therefore navigate their belonging to and residing in their areas, and the limits of what they are able to deliver.

It is not clear from the data how prevalent these practices are or to what extent they might be a source of tension and struggle between residents. It is possible, for example, that some leaders might privately take a different stand regarding illegal connections, or that some residents receive preferential treatment. Indeed, it may even be a mechanism for local patronage where the leaders defend those who in turn support them, and possibly report on those who do not. But these practices illuminate some of the contradictions and challenges with which leaders and residents of informal settlements must live.

\section{Discussion}

The aim of this paper has been to explore how community leadership is socially constructed through specific practices, and how leaders emerge and act as intermediaries between their communities and the City. From the community leadership literature, we established that community leadership is unique insofar as it is situated outside of formal organizational contexts where relations are in part defined by clear agendas and hierarchical structures. Rather, community leadership operates between different contexts and their potentially conflicting social norms and practices, which raises challenges for leaders who must continually work to sustain their legitimacy as leaders. In this section, we discuss what the four practices identified in this research show about how leaders fulfil their intermediary roles. In particular, we argue leaders' practices reflect pragmatic improvisations to find what works in between the pressures from 'above' and 'below'. Their practices also emerge out of, and reproduce relations of dependence and interdependence, which in fact reinforce their roles as intermediaries.

\section{Community leadership as practice: a tenuous, continuous and contextual practice}

The four practices illuminate a certain tension at the centre of community leaders' intermediary role, also picked up by Bénit-Gbaffou and Katsaura (2014). Practices that produce leadership 
can complement or contradict one another. Certain practices undertaken in a specific time and place can gain legitimacy for leaders with both the community and the City as their interests and objectives intersect and they find mutual benefit in a particular outcome (such as when service faults are addressed). Some practices may benefit or 'empower' only the community or the City, and thereby reinforce legitimacy with the one while undermining it with the other. Alternatively, a leader may do things that strengthen their legitimacy with the City, and do other things that simultaneously weaken or undermine that legitimacy (e.g. addressing vandalism and defending illegal connections). A similar tension applies to their relations with their communities in how they prevent vandalism but allow illegal connections. This suggests leaders' intermediary roles remain tenuous since they depend on such relational practices with residents and the officials for the ongoing sustenance of their leadership. Stated otherwise, they are never in a "fixed position of superiority" (Schweigert, 2007) or in a single, static power relation, and there is no clear, concrete agenda they must follow in either direction.

This aligns with the extant community leadership research that finds leaders employ a mix of oppositional and collaborative strategies (Oldfield and Stokke, 2007), fulfilling their intermediary role either as champions, opponents, or pragmatists (Purdue et al., 2000). We would add, the choice of how they do so is itself a pragmatic one which they continually make. It also resonates with theorizations of leadership-as-practice as produced by the non-linear flow of activity involving ongoing divergences and conflicts (Crevani et al., 2010). Alvesson and Jonsson's (2018: 51-55) study of leadership in middle manager work similarly depicts leadership practices as multifaceted and "episode driven". It is thus less about a particular set of competencies or behaviours than it is about an "appreciation of context", with resultant adaptive practices that are complex, iterative, and even contradictory (Tourish, 2014: 93).

Despite the distinct features of community leadership and community contexts which, we believe, contribute to these dynamics (and discuss in more detail below), we cannot definitively conclude from the evidence that this is unique to the practice of community leadership. There are potential similarities, as noted above, between community leaders as intermediaries and middle managers in organizations (Kempster and Gregory, 2017), or leaders of cross-sectoral or inter-organizational collaboration (Crosby and Bryson, 2010; Connelly, 2007). Middle managers and leaders of collaborative initiatives are also situated in an 'in between' space where they must navigate different institutional systems, practices and agendas. 
There are still two important ways in which community leadership are likely to differ, however. First is the fact that middle managers and collaborative leaders are likely to be appointed. They would thus be able to rely on their positional power to fulfil their intermediary roles. Although they must also navigate between different interests, they would ultimately have to account to a particular 'entity', whether this is their organization's or the collaboration's purpose, or the dictates of top management. Community leaders, on the other hand, are not appointed but rather elected or emerge informally as leaders. It is precisely for this reason that they must work to continually maintain their legitimacy as leaders through pragmatic and relational work. This is complicated by the fact that local contexts, particularly informal settlements, are themselves highly fluid, with shifting members (residents) and agendas. For community leaders, the work is never done, and the questions around 'leadership for what' and 'for whom', never fully answered.

\section{Community leaders as intermediaries: the social construction of relations of dependence}

Although there may not be a specific organizational context shaping community leaders' practices, their practices do emerge within the broader context where informality and municipal systems and practices intersect. For informal settlements, limited access to communal service infrastructure means service issues are prominent in daily life. The leaders' practices can therefore be understood against a more or less stable background of community practices through which people share basic services. This includes social practices around reporting service faults, but also vandalizing infrastructure or making illegal service connections.

In the midst of these practices, the City has introduced a new reporting system that re-orients the 'flow of activity' (Kempster and Gregory, 2017), and through which individual leaders and officials (and the relations between them) gain importance and influence. The introduction of the call centre and notification number in particular has shifted power in the system away from the ward councillor's structural or 'positional power' (Bass, 1990), towards individual residents and community leaders. This is an intentional aim of the system - to provide equal access for residents across the City. But many informal settlement residents continue to rely on local leaders to report on their behalf. The system and practices around reporting thus reinforce the relevance of individual leaders and the power asymmetries between leaders and residents as leaders can control these information flows (McCauley et al., 2015). But these reporting 
practices also reflect socio-historical patterns where local leaders have been expected to take on such intermediary roles in the past (Drivdal, 2016).

This practice and relation of dependence is not simply an outcome of leaders' intentional efforts. They are also outcomes of the realities of living in informality, and the inadequacies of the reporting system in such contexts: the call number is not well-known; providing the precise location of a service issue can be difficult; and there are no guarantees that officials will be able to enter and/or find the issue. Managing these challenges in order to 'get things done' is also not only achieved through the practices of individual leaders. Residents report to local leaders (as part of established patterns of behaviour in informal settlements). Leaders bring their local knowledge and understanding of how the municipal systems work, as well as their contacts with officials. And officials 'play their part' by trusting and responding to local leaders and bringing their technical knowledge.

Through the lens of L-A-P, community leaders' intermediary practices are thus part and parcel of a broader array of intersecting practices. Leaders emerge as intermediaries, but as part of a broader kind of collective agency around service maintenance goals. Although not quite a non-hierarchical, collaboration where efforts neatly coalesce and people act either democratically or in unison, it is also not simply a product of power 'from the top', or even 'from the middle'. Power permeates and shifts through these practices, while the practices give expression to and reinforce existing relations of dependence and interdependence.

This dynamic manifests, for instance, in the recursive relation between the agency and legitimacy of the leaders and that of officials produced in this context. Reporting problems and meeting officials have emerged as opportune ways for the leaders to deliver, gain legitimacy, and thereby maintain their roles as intermediaries. Yet the ability of both leaders and officials to address service issues - an objective they arguably share - are intertwined and depends on each other's ability and legitimacy. Leaders' depend in their reporting practices on the response from officials, and officials depend on community leaders in meeting their service maintenance goals.

\section{Intermediary practices: pragmatic improvisations to find what works}

In the informal settlements in our research, the leaders' practices in the management of services display a particularly supportive role insofar as they help both residents and the City in local governance processes. They assist residents to 'penetrate' local government, which 
is often seen as distant and cumbersome. They also assist officials to 'penetrate' the community, usually perceived as amorphous and disorganized (Bénit-Gbaffou and Katsaura, 2014). In doing so, however, their practices also maintain the distance between the City and community, again (re)producing the dependencies that sustain their roles as intermediaries.

At the same time, however, local leaders remain situated in and shaped by broader inequalities that define the relation between informal settlement communities, on the one hand, and the state, on the other. In this sense, the four practices illuminate how community leadership emerges in the context of broader governance systems, where leaders confront the limits of their ability to deliver. They must navigate the difficulties of belonging, in the face of their inability to secure 'real' transformation. In response, leaders work to improvise and find 'what works'. Some of their practices support the functioning of the formal system. Contacting and meeting officials, for instance, although an informal and emergent practice, has also become integral to the effective operation of the City's maintenance system. Their practices around making and supporting illegal connections, on the other hand, implicitly challenge the formal governance system. Although beyond the scope of this paper, illegal service connections have been used by social activists and communities across South Africa to challenge service delivery policies like full cost-recovery (Everatt et al. 2010). Such acts have been described as "officially illegal yet morally appropriate" acts of citizenship in the struggle for recognition in post-apartheid South Africa (Everatt et al. 2010: 224). The practices among local leaders in our research could therefore again be understood as part of broader, 'collective' forms of agency, emerging on the margins of what is possible for community leaders working as intermediaries within the formal system.

Taken together, community leadership practices involve the pragmatic working-out of local possibilities, which can have the effect of mitigating one power differential while creating or reproducing another. These practices involve on-going, pragmatic improvisations that emerge through relational and collective patterns of interaction. The analysis further suggests leadership-as-practice can both reinforce and challenge power differences and established ways of doing things, thus encompassing the dynamic interplay of power relations at multiple levels.

\section{Conclusion}

This article has explored how community leadership emerges and operates through four practices in relation to service maintenance, in order to understand how community leaders 
fulfil their intermediary role between communities and government. We have brought together the community leadership and leadership-as-practice literatures, in combination with empirical data on how community leaders in informal settlements in Cape Town get involved in water and electricity services. Informal settlement contexts are rarely examined in the literature on community leadership or leadership-as-practice, yet represents a pervasive characteristic of developing countries. We found community leaders' legitimacy as leaders emerges through these four practices in both complementary and contradictory ways. Through these practices, the leaders fulfil their intermediary roles, and reproduce relations of dependence and interdependence that sustain those very roles. They also do so in ways that, at times, support the effective functioning of the municipal service maintenance system, and at other times, challenge that same system. Community leadership-as-practice thus involves the pragmatic working-out of what is possible at the intersection of relational and collective patterns of action and the City's formal maintenance and reporting systems. As a key point of interaction between government and communities, service maintenance can thus be understood (and further considered) as an important context for the emergence of community leadership and leadership-as-practice. Understanding the complex roles of community leaders in such processes is also important as the challenges of rapid and growing urbanization will require more and better intersections between formal government systems 'from above', community experiences 'from below', and community leadership 'in between'.

\section{Acknowledgements}

We would like to thank Professor Brad Jackson for his helpful comments on earlier versions of this paper.

\section{Funding}

This research is based on work funded by the Cities Support Programme (CSP) led by National Treasury in South Africa (RFP 13/2012).

\section{Declaration of conflicting interests}

The authors declare no potential conflicts of interest with respect to the research, authorship and/or publication of this article.

\section{References}

Alvesson $M$ and Jonsson A (2018) The bumpy road to exercising leadership: Fragmentations in meaning and practice. Leadership 14(1): 40-57. 
Bass BM (1990) Bass and Stogdill's handbook of leadership: Theory, research, and managerial applications. $3^{\text {rd }}$ edition. New York: The Free Press.

Bénit-Gbaffou C and Katsaura O (2014) Community leadership and the construction of political legitimacy: unpacking Bourdieu's 'political capital' in post-apartheid Johannesburg. International Journal of Urban and Regional Research 38(5): 1807-1832.

Brail S and Kumar N (2017) Community leadership and engagement after the mix: The transformation of Toronto's Regent Park. Urban Studies 54(16): 3772-3788.

Brint S (2001) Gemeinschaft Revisited: A critique and reconstruction of the community concept. Sociological Theory 19(1): 1-23.

Buire C (2011) 'Bringing government closer to the people'? The daily experience of subcouncils in Cape Town. Journal of Asian and African Studies 46(5): 465-478.

Cameron R (2005) Metropolitan restructuring (and more restructuring) in South Africa. Public Administration and Development 25(4): 329-339.

Carroll B, Levy L and Richmond D (2008) Leadership as practice: Challenging the competency paradigm. Leadership 4(4): 363-379.

Connelly D (2007) Leadership in the collaborative interorganizational domain. International Journal of Public Administration 30(11): 1231-1262.

Crevani L and Endrissat N (2016) Mapping the leadership-as-practice terrain: comparative elements. In: Raelin J (ed) Leadership-as-practice: theory and application. New York: Routledge, pp.21-49.

Crevani L, Lindgren $M$ and Packendorff $\mathrm{J}$ (2010) Leadership, not leaders: on the study of leadership as practices and interactions. Scandinavian Journal of Management 26(1): 77-86.

Crosby B and Bryson J (2010) Integrative leadership and the creation and maintenance of cross-sector collaborations. The Leadership Quarterly 21(2): 211-230.

Collinson M (2018) What's new about Leadership-as-Practice? Leadership 14(3): 363-370.

Drivdal L (2016) Community leadership in urban informal neighbourhoods: Micro-politics and micro-administration in informal settlements in Cape Town. Urban Forum 27(3): 275-295.

Endrissat N and von Arx W (2013) Leadership practices and context: Two sides of the same coin. Leadership 9(2): 278-304.

Everatt D, Marais H and Dube N (2010) Participation... for what purpose? Analysing the depth and quality of public participation in the integrated development planning process in Gauteng. Politikon 37(2-3): 223-249.

Fisher K and Robbins CR (2015) Embodied leadership: Moving from leader competencies to leaderful practices. Leadership 11(3): 281-299. 
Fletcher J (2004) The paradox of postheroic leadership: An essay on gender, power, and transformational change. The Leadership Quarterly, 15(5): 647-661.

Ford J (2016) Gendered relationships and the problem of diversity in leadership-as-practice. In: Raelin J (ed) Leadership-as-practice: theory and application. New York: Routledge, pp.223-241.

Gambrell KM (2016) Lakota women leaders: Getting things done quietly. Leadership 12(3): 293-307.

Govender I (2016) Monitoring and evaluating service delivery as a wicked problem in South Africa. Journal of Human Ecology 55(1.2): 21-34.

Gullo S, Galavotti C and Altman L (2016) A review of CARE's Community Score Card experience and evidence. Health Policy and Planning: 1-12.

Ho L, Labrecque G, Batonon I, Salsi V and Ratnayake R (2015) Effects of a community scorecard on improving the local health system in Eastern Democratic Republic of Congo: qualitative evidence using the most significant change technique. Conflict and Health 9(27): $1-11$.

Housing Development Agency (HDA) (2013) South Africa: Informal settlements Status. Report for the Housing Development Agency, SA, August 2013. Available at:

http://www.thehda.co.za/uploads/files/HDA_South_Africa_Report_Ir.pdf (accessed 4 August 2019).

ismaps.org.za (No date) Struggle for dignity in Cape Town's informal settlements: the facts. Available at: ismaps.org.za (accessed 4 August 2019).

Ivory B (2008) Indigenous leaders and leadership: agents of networked governance. In: Hunt J, Smith D, Garling S and Sanders W (eds). Contested Governance: culture, power and institutions in Indigenous Australia. Canberra: ANU Press, pp.233-262.

Kempster S and Gregory S (2017) 'Should I stay or should I go?' Exploring leadership-aspractice in the middle management role. Leadership 13(4): 496-515.

Kotter JP (1990) A force for change: how leadership differs from management. London: Collier Macmillan.

Krefting $L$ (1991) Rigor in qualitative research: the assessment of trustworthiness. American Journal of Occupational Therapy 45(3): 214-222.

Lauzon A (2017) Community leadership and global climate change: the case of rural and small communities. In: Wang V (ed) Strategic Leadership. Charlotte, NC: Information Age Publishing, pp.143-164.

Lin $\mathrm{Y}$, Kelemen $\mathrm{M}$ and Kiyomiya $\mathrm{T}$ (2017) The role of community leadership in disaster recovery projects: Tsunami lessons from Japan. International Journal of Project Management 35: 913-924.

Madumo OS (2012) Contextualising leadership challenges in municipalities. African Journal of Public Affairs 5(3): 82-92. 
Majee W, Jooste K, Aziato L and Anakwe A (2017) Scars of disengagement: perspectives on community leadership and youth engagement in rural South Africa. Global Health Promotion 26(3): 5-14.

Martiskainen M (2017) The role of community leadership in the development of grassroots innovations. Environmental Innovation and Societal Transitions 22: 78-89.

Masafu C (2015) The design of inclusive participatory systems in highly diverse societies: a case study on the usage of the C3 notification system in Langa, Cape Town. Unpublished Masters Thesis. University of the Western Cape, South Africa.

Massey R (2015) Integral theory: a tool for mapping and understanding conflicting governmentalities in the upgrading of Cape Town's informal settlements. Urban Forum 26(3): 303-319.

McCauley, MP, Ramanadhan, S and Viswanath, K (2015) Assessing opinions in community leadership networks to address health inequalities: a case study from Project IMPACT. Health Education Research 30(6): 866-881.

McFarlane C (2008) Sanitation in Mumbai's informal settlements: state, 'slum', and infrastructure. Environment and Planning A 40: 88-107.

Munro $\mathrm{H}$ (2008) When do community leaders make a difference? Exploring the interaction of actors and institutions. Unpublished PhD Thesis. University of Birmingham, UK.

Nicolini D (2013) Practice theory, work, and organization: an introduction. Oxford: Oxford University Press.

Nowell B, Izod A, Ngaruiya K and Boyd N (2016) Public service motivation and sense of community responsibility: comparing two motivational constructs in understanding leadership within community collaboratives. Journal of Public Administration Research and Theory 26(4): 663-676.

Oldfield S and Stokke K (2007) Polemical politics, the local politics of community organising, and neoliberalism in South Africa. In: Leitner H, Peck J and Sheppard ES (eds) Contesting neoliberalism: The urban frontier. Connecticut: Guildford Press, pp.139-156.

Onyx $\mathrm{J}$ and Leonard RJ (2011) Complex systems leadership in emergent community projects. Community Development Journal 46(4): 493-510.

Ospina S (2017) Collective leadership and context in public administration: Bridging public leadership research and leadership studies. Public Administration Review 77(2): 275-287.

Purdue D, Razzaque K, Hambleton R and Stewart M (2000) Community leadership in area regeneration. Bristol: The Policy Press.

Raelin JA (2011) From leadership-as-practice to leaderful practice. Leadership 7(2): 195-211.

Raelin JA (2016a) Imagine there are no leaders: Reframing leadership as collaborative agency. Leadership 12(2): 131-158. 
Raelin JA (2016b) Introduction. In: Raelin JA (ed) Leadership-as-practice: theory and application. New York: Routledge, pp.1-17.

Raelin JA, Kempster S, Youngs H, Carroll B and Jackson B (2018) Practicing leadership-aspractice in content and manner. Leadership 14(3): 371-383.

Rittel H and Webber M (1973) Dilemmas in a general theory of planning. Policy Sciences 4(2): 155-169.

[Author names omitted for peer review] (2019) [Chapter details omitted for peer review] In: Fynn A, Kramer S and Laher S (eds) Transforming Research Methods in the Social Sciences: case studies from South Africa. Johannesburg: Wits University Press, pp.375-392.

Schatzki T, Knorr-Cetina K, and Von Savigny E. (2001) The practice turn in contemporary theory. London: Psychology Press.

Schweigert FJ (2007) Learning to Lead: Strengthening the Practice of Community Leadership. Leadership 3(3): 325-342.

Simpson B (2016) Where's the agency in leadership-as-practice? In: Raelin J (ed) Leadershipas-practice: theory and application. New York: Routledge, pp.159-177.

Storey A (2014) Making experience legible: Spaces of participation and the construction of knowledge in Khayelitsha. Politikon 41(3): 403-420.

Thompson L and Nleya N (2010) Passivity or protest. In: Schattan V, Coelho P and von Lieres $\mathrm{B}$ (eds) Mobilizing for democracy: citizen action and the politics of public participation. London: Zed Books, pp.223-242.

Tourish D (2014) Leadership, more or less? A processual, communication perspective on the role of agency in leadership theory. Leadership 10(1): 79-98.

Uhl-Bien M (2006) Relational leadership theory: Exploring the social processes of leadership and organizing. The Leadership Quarterly 17(6): 654-676.

Uhl-Bien M and Ospina S (eds) (2012) Advancing relational leadership research: A dialogue among perspectives. Charlotte, North Carolina: Information Age.

von Schnitzler A (2008) Citizenship prepaid: water, calculability, and techno-politics in South Africa. Journal of Southern African Studies 34(4): 899-917.

Welton AD and Freelon R (2018) Community organizing as educational leadership: lessons from Chicago on the politics of racial justice. Journal of Research on Leadership Education 13(1): 79-104.

Williams DS, Costa MM, Celliers L and Sutherland C (2018) Informal settlements and flooding: identifying strengths and weaknesses in local governance for water management. Water $10: 1-21$.

Woods, PA (2016) Democratic roots: feeding the multiple dimensions of leadership-aspractice. In: Raelin $\mathrm{J}$ (ed) Leadership-as-practice: theory and application. New York: Routledge, pp.70-88. 
